\title{
EL INCENDIO DE LA BIBLIOTECA DE ALEJANDRÍA POR LOS ÁRABES: UNA HISTORIA FALSIFICADA
}

\author{
Ricardo H. Elía \\ Centro Islámico de la República Argentina
}

Resumen: Los árabes nunca pudieron haber quemado la Biblioteca de Alejandría en 642 d. C. por la sencilla razón de que ésta hacía 250 años que ya no existía. Había sido destruida, en 391 por los mismos fanáticos que 25 años después asesinaron a Hipatia, la mujer más lúcida de la Antigüedad. Esta investigación está basada en fuentes que precisan el origen y la razón de la falsificación.

Palabras claves: Biblioteca, califa, bibliología, biblioclasta, bibliofilo.

\section{FIRE FROM THE LIBRARY OF ALEXANDRIA BY THE ARABS: A HISTORY FAKE}

\begin{abstract}
The Arabs never could have burned the Library of Alexandria in 642 A.D. for the simple reason that it was 250 years that no longer existed. It had been destroyed in 391 by the same fanatics who 25 years later murdered Hypatia, the most clear-thinking woman of Classical times. This research is based on sources which specifies the origin and the reason of the forgery.
\end{abstract}

Key words: Library, caliph, bibliology, biblioclast, bibliophile.

Recibido: 23.01.13- Aceptado: 12.03 .13

Correspondencia: Ricardo H. Elía. ricardohselia@yahoo.com.ar

Secretario de Cultura y Director del Departamento de Estudios Históricos del Centro Islámico de la República Argentina. Av. San Juan 3053 (1233)

Buenos Aires, Argentina. Tel. (54-11) 4931-3577 (interno 113). 
lejandría fue fundada cerca del delta del Nilo por Alejandro el Grande
(356-323 a. C.) en el año 332 a. C. La conocida por el sobrenombre
de "novia del Mediterráneo", se encuentra $220 \mathrm{~km}$ al noroeste de El Cairo, capital de República Árabe de Egipto. El lugar elegido fue un poblado de pescadores llamado Rakotis que se encontraba frente a una isla llamada Faro por los griegos, donde se construyó el Faro de Alejandría a fines del siglo III a. C.

«Una isla hay luego en el proceloso mar delante de Egipto: Faros la llaman», le dijo en sueños un sabio de blancos cabellos a Alejandro. Fue, según supone el historiador griego Plutarco, la manera elegida por el poeta Homero de recordarle al estratega macedonio unos versos de "La Odisea" y de indicarle el lugar donde debía situarse la capital de su imperio. Así, mediante un hecho lleno de magia, se narra la fundación de la primera y la más célebre de las urbes que llevarían el nombre de Alejandría, la situada en la desembocadura del Nilo, en un enclave especialmente propicio por su posición estratégica.

En el Mü̈âm al-buldân (Diccionario de las comarcas) del historiador Yaqut Abd Allah al-Hamaui ar-Rumi (1179-1229), griego del Asia Menor que adoptó el Islam, se menciona que Alejandro el Macedonio fundó trece ciudades a las cuales puso su nombre, aunque posteriormente solo lo conservaba (en el siglo XIII d. C.) la gran ciudad egipcia.

La belleza de la ciudad no pudo ser disfrutada por Alejandro. Su muerte prematura le impidió ver la construcción del magnífico urbanismo diseñado por el arquitecto y urbanista Dinócrates de Rodas que, inspirándose en ciudades griegas del siglo $\mathrm{V}$ a. C., ideó un trazado en manzanas que sorprende por su modernidad. Según su Plan hipodámico, vías secundarias de número indeterminado cruzaban los ejes principales constituidos por la Vía Canópica (de este a oeste) y la Avenida de Soma (de norte a sur): una verdadera cuadrícula o ciudad en damero. Alejandría se convertiría en el centro de la cultura y del refinamiento del mundo antiguo durante la época de la dinastía de los Ptolomeos (305-30 a. C.). 


\section{La fundación de la Biblioteca-madre}

Ptolomeo I (367-283 a. C.), llamado Soter (el 'Salvador'), que había sido uno de los mejores generales de Alejandro, inició en Egipto a fines del siglo IV a. C. una dinastía de sangre griega de la cual la famosa Cleopatra sería el último soberano. El primer soberano ptolemaico reinó entre 305-285 a. C.

Según lo manifiesta el obispo griego san Ireneo (c.130-c.208), Ptolomeo fundó en Alejandría la "Biblioteca-Madre", en el Bruchión (distrito real), cerca del puerto, que sería conocida como la Primera Biblioteca, y ordenó la construcción del Faro, una de las Siete Maravillas del Mundo Antiguo. A partir de entonces, Alejandría representará el nuevo espíritu del mundo helenista, en reemplazo de Atenas.

La Biblioteca alejandrina se estableció en el año 297 a. C. y fue por iniciativa del filósofo peripatético Demetrio de Falero (350-282 a. C.), discípulo de Teofrasto de Lesbos (ca. 371-ca. 287 a. C.) quien fue su primer bibliotecario. Para diferenciarla de la posterior, surgida unos 50 años después, será identificada por los especialistas como la Biblioteca-madre.

Ptolomeo II (308-246 a. C.), llamado Filadelfo ('el que ama a su hermana'), hijo de Ptolomeo Soter, que gobernó en Egipto de 285 a 246 a. C., llevó a cabo el proyecto de su padre construyendo el Faro y el Museo ("institución de las musas"), este último considerado como la primera universidad del mundo en su sentido moderno, y además compró las bibliotecas de Aristóteles y Teofrasto.

Por entonces los manuscritos se escribían sobre láminas de papiros, un vegetal muy abundante en Egipto, que crece en las adyacencias del Nilo. Según nos informa Plinio el Viejo (23-79 d. C.) en su Historia Natural, a causa de la rivalidad de la Biblioteca de Pérgamo con la Biblioteca de Alejandría. La de Pérgamo fue creada por Eumenes II que reinó entre 197-160 a. C. La palabra griega "bibliotheke" identificaba cualquier estante, anaquel, armario o nicho en la pared que pudiera ser usado para almacenar rollos. Incluso los rollos de papiros se guardaban en cestos y vasijas.

Ptolomeo Filadelfo prohibió la exportación de papiro; en consecuencia, en Pérgamo se inventó el pergamino; éste se conseguía preparando la piel de cordero, de asno, de potro y de becerro, y cuando más lisa y suave fuera la piel que se utilizaba, más se la apreciaba. El pergamino era más resistente que la hoja de papiro y además ofrecía la ventaja que se podía escribir sobre ambos lados. 
Por entonces, esta primera biblioteca poseía trece salas de conferencias que podían albergar a cinco mil estudiantes lo que habla de las dimensiones del complejo. La Biblioteca de Pérgamo fue fundada por el rey Atálo I de Tíos (de 241 a 197 a. C.). Su sucesor, Eumenes II, soberano entre 197-160 a. C., enriqueció esa biblioteca, imitando los parámetros del complejo alejandrino.

\section{La fundación de la Biblioteca-hija}

Ptolomeo III (ca. 282-222 a. C.), llamado Everguétis (el 'Benefactor') será el fundador de la "Biblioteca-hija" en el Serapeum (templo dedicado a Serapis, una divinidad que era una combinación de Osiris y Apis), en la Acrópolis de la colina de Rakotis, que sumará 700.000 volúmenes según el escritor latino Aulio Gelio (ca. 123-ca. 165 d. C.), el autor de las Noches Áticas. Aunque hay que tener sumo cuidado a la hora de interpretar este número. Cuando los helenos hablan de volúmenes se referían a rollos de papiros, y cada uno de ellos equivalía a unas 64 páginas actuales, así que se necesitaban muchos para formar un libro. Difícilmente una obra cabía en un solo rollo.

Se sabe que desde el principio la Biblioteca-madre fue un apartado al servicio del Museo. Pero más tarde, cuando esta entidad adquirió gran importancia y volumen, hubo necesidad de crear un anexo cercano. Se cree que esta segunda biblioteca fue creada en la colina del barrio de Rakotis (hoy llamada Karmuz), en el lugar de Alejandría más alejado del mar; cerca del perímetro sur de la urbe, concretamente, en el antiguo templo erigido por los primeros Ptolomeos a Serapis, llamado el Serapeo, considerado como uno de los edificios más bellos de la Antigüedad.

Cuando Ptolomeo Soter decidió crear la Biblioteca de Alejandría, eligió como modelo la Biblioteca ateniense de Aristóteles de Estagira (384-322 a. C.), el gran filósofo y preceptor de Alejandro el Grande. La idea de los primeros alejandrinos fue que la biblioteca contara con una copia de todas las obras escritas en griego, pero pronto se pensó que era mejor adquirir una copia de toda obra de interés escrita en cualquier idioma; por último, se abandonó el concepto mismo de "obra de interés» para tratar de alcanzar a la universalidad toda, o sea, conseguir un ejemplar de toda obra existente. Así, la Biblioteca-madre y la Biblioteca-hija engrandecieron su caudal principalmente con la confiscación de cuanto manuscrito se encontrara a bordo de todo navío fondeado en el puerto de Alejandría, devolviéndose tan sólo una copia del mismo. Estos detalles fueron explicados por el célebre médico Claudio Galeno en el siglo II d. C. 


\section{La primera biblioteca universal de la historia}

La biblioteca de Alejandría llegó a ser primera biblioteca universal de la historia. El primer inventario realizado que estuvo a cargo de Demetrio de Falero, arrojó la existencia de aproximadamente cuatrocientos mil rollos, que sucesivamente aumentaron a quinientos mil, y en tiempos del gramático y poeta Calímaco de Cirene (310-240 a. C.), que enseñó en Alejandría y trabajó en la biblioteca, de la que seguramente fue director a principios del siglo III a. C., la cifra subía a setecientos mil.

Calímaco habla de rollos symmigeîs (¿compuestos?) y amigeîs (¡simples?) según lo asevera el filólogo bizantino Juan Tzetzés (ca.1110- ca.1180), Se ignora el significado preciso de las palabras symmigeîs y amigeîs con las cuales se dividía físicamente la colección.

Con el mecenazgo inicial de Ptolomeo Filadelfo, precisamente en el Museo, entre principios del siglo III a. C. hasta finales del siglo II a. C. se realizó la traducción al griego de la Biblia hebrea, tarea que fue encomendada y llevada a cabo por setenta y dos jajamim (en hebreo, "sabios") de Egipto; versión que conocemos con el nombre de Septuaginta o traducción de los setenta. Este hecho es sumamente significativo, pues esclarece sobre el profundo conocimiento que poseían los griegos de los judíos antes del nacimiento de Jesús, el hijo de María.

\section{Los seis primeros bibliotecarios}

Los seis primeros bibliotecarios o encargados de la Biblioteca de Alejandría, puesto de gran responsabilidad y sumamente honorífico, fueron (entre paréntesis, la duración en el cargo): 1. Zenódoto de Éfeso (285-270 a. C.), realizador de numerosas clasificaciones de poetas épicos, un diccionario homérico y la primera edición científica de la Ilíada y la Odisea; 2. Apolonio de Rodas (270-245 a. C.); 3. Eratóstenes de Cirene (276-194 a. C.) matemático, astrónomo y geógrafo que calculó el tamaño de la Tierra con mucha precisión; 4. Aristófanes de Bizancio (201-189), lingüista por excelencia, escribió comentarios a Eurípides y a Aristófanes de Atenas, a él se le debe, asimismo, la división de la sobras de Platón en trilogías y, como lexicógrafo, explicó las diversas acepciones de palabras en autores antiguos conforme a los dialectos; 5. Apolonio Pantógrafo (189-175 a. C.); y 6. Aristarco de Samotracia (175-145 a. C.), que fue uno de los primeros escoliastas (del griego, sjólion, comentario; es decir, comentarista) de la historia, llevando a cabo una tarea que conocemos como «ediciones comentadas», 
habiendo redactado cerca de ocho cientos volúmenes, asimismo se considera a este erudito como el fundador de la investigación científica en estudios clásicos y formador de un importante grupo de discípulos, entre ellos Calístrato, Herminio (autor de una manual de mitología, una Etimología, etc.), Ammonio, Dionisio de Tracia, Tiranio y Dídimo. Véase sobre el particular, el notable trabajo del helenista argentino Saúl Antonio Tovar (1938-2006), «Biografía de la Lengua Griega: Sus 3000 años de continuidad» (Santiago de Chile: Centro de Estudios Griegos, Bizantinos y Neohelénicos "Fotios Malleros", 1990, pp. 21-40).

\section{Los sabios de Alejandría en la Biblioteca}

Los sabios e investigadores mas destacados de la época helenística vivieron y trabajaron en la Biblioteca de Alejandría, aprovechando sus inestimables tesoros para fundamentar sus propios trabajos o descubrimientos y suscitando a su vez un movimiento intelectual y cultural que abarcaba todos los ámbitos del saber de aquella ecumene.

Entre ellos debemos mencionar a Aristarco de Samos (ca. 310 a. C.- ca. 230 a. C.), el primer científico que se conozca, que propone el modelo heliocéntrico del Sistema Solar, colocando el Sol, y no la Tierra, en el centro del universo conocido; a Euclides (ca. 325-ca. 265 a. C.), el gran matemático que sentó las bases de la geometría de los siguientes 23 siglos; a Hiparco de Nicea (190120 a. C.), junto a Claudio Ptolomeo, el astrónomo más importante de la antigüedad que fue además director de la biblioteca; a Herón el Viejo (ca. 10-70 d. C.), que escribió varios libros de mecánica fue creador de numerosos inventos e ingenios como la dioptra, el odómetro y la eolípila, la primera máquina térmica de la historia, precursora de la máquina de vapor; a Claudio Ptolomeo (90-168 d. C.), que fundó la cartografía, impulsó la astronomía y escribió obras como Almagesto, geografía, Gran Sintaxis, etc.; y a Claudio Galeno de Pérgamo (131-201 d. C.), el celebérrimo erudito que escribió los primeros tratados de medicina, facultativo de gladiadores en su ciudad natal hacia el año 157, su obra, heredera de las teorías de Hipócrates y Aristóteles, perduró como fuente del saber médico hasta mediados del siglo XVII, y su nombre quedó como sinónimo de médico.

\section{El incendio de la biblioteca durante la invasión romana}

Entre los años 88 y 44 a. C., Roma, la orgullosa república del Tíber, se encuentra sumida en guerras civiles. Las más furiosas batallas se sucedieron 
entre 49-46 a. C. entre los partidarios de los triunviros Cneo Pompeyo (10648 a .C.) y Julio César (100-44 a. C.). Mientras tanto en Egipto, la dinastía ptolemaica había caído en la degradación total. hacia el ańo 51 a. C., el trono estaba ocupado por una reina de solo 17 ańos, Cleopatra VII (69-30 a. C.), apodada Filopátor ("Amiga de su padre"), hija de Ptolomeo XII (117-51 a. C.), llamado Auletes (el "Flautista"), y de Cleopatra V (ca. 95 a. C. - ca. 69/57 a. C), llamada Trifena ("delicadeza”), que compartía el poder simultáneamente con sus hermanos Ptolomeo XIII Theós Filopátor (ca. 61- ca. 47 a. C.), de diez años, y Ptolomeo Theós Filopátor II (ca. 59 a. C. -44 a. C.), de apenas ocho años.

Cuando César llegó a Alejandría con 4 mil hombres en persecución de Pompeyo en octubre del año 48 a. C. (éste ya había sido arteramente asesinado por orden de la infantil familia ptolemaica para congraciarse con el dictador romano), fue sitiado durante el invierno boreal por los alejandrinos hasta que fue rescatado en marzo del año 47 a. C. por dos legiones procedentes del Asia Menor y el ejército de su aliado Mitrídates I, rey del Bósforo.

A pesar de que César era «el amo del mundo» y la propia Cleopatra y sus hermanos lo favorecían, luego de que el hechizo de su llegada se desvaneciera, los alejandrinos, conscientes de que el general latino se había adelantado a sus legiones y disponía de escasas fuerzas, iniciaron una resistencia desesperada conducidos por el general Aquilas que disponía de un ejército de veinte mil soldados, intentando aniquilarlo antes de que llegasen refuerzos.

Atacado César por todos sus flancos, se atrincheró en el palacio de Cleopatra resuelto a combatir hasta las últimas consecuencias. La insurrección alejandrina contra los invasores romanos tuvo cinco etapas: 1 . El asedio del palacio; 2 . Primer combate naval; 3. Segundo combate naval y pérdida de la isla de Faro; 4. Batalla del dique; 5. Batalla junto al Nilo.

Durante la primera etapa se produciría la primera destrucción de la Biblioteca de Alejandría, es decir de la llamada Biblioteca-madre. El escritor británico Edward Morgan Forster (1879-1970), en su pormenorizado estudio sobre la ciudad fundada por el Gran Alejandro, puntualiza: «El asedio estaba triunfando en tierra pero fracasando en el mar cuando César bajó inesperadamente por los muelles del Puerto Oriental e incendió la flota alejandrina (72 naves). Las llamas se extendieron al Museion y la Biblioteca fue destruida por el fuego; ... las llamas que se extendieron de la flota surta en el Gran Puerto a los muelles y edificios portuarios 
destruyeron gran número de libros que se conservaban alli, ya fuese en espera de su entrega a la Biblioteca o de su exportación a ultraman ${ }^{1}$.

Según los historiadores más relevantes, más de cuarenta mil rollos de la biblioteca se perdieron para siempre en el incendio causado por la táctica militar cesariana. El escritor, filósofo y político romano de origen hispánico Lucio Anneo Séneca el Joven (4 a. C.-65 d. C.) en su obra De tranquillitate animi (Acerca de la tranquilidad del ánimo), en el Capítulo IX del Libro Tercero, afirma: «Cuarenta mil cuerpos de libros se abrasaron en la ciudad de Alejandría»

Por su parte, el historiador griego Plutarco (ca. 46/50-120 d. C.), autor de "Vidas Paralelas" (una serie de biografías de griegos y romanos famosos, elaborada en forma de parejas con el fin de comparar sus virtudes y defectos comunes), asevera: "César, amenazado de verse interceptado por la flota, se vio obligado a rechazar el peligro mediante el fuego, que, al propagarse desde los arsenales, destruyó la gran biblioteca» ${ }^{2}$. Eminentes historiadores romanos como Amiano Marcelino (ca. 330/335-ca. 400 d. C.) -en su Res Gestarum Libri XXXI, 22, 16, 13- corroboran el episodio. Parece ser que luego de estos graves sucesos la biblioteca siguió funcionando. Estrabón describe el Museo en la época de Augusto y nos informa de ninguna anormalidad.

Suponiendo, como algunos investigadores dicen -entre ellos el filólogo italiano Luciano Canfora ${ }^{3}$-, que la hoguera cesariana consumió parcialmente la Biblioteca, o que el fuego se limitó a los barcos y almacenes navales donde se hallaban depositados decenas de miles de rollos, esto no disculpa la responsabilidad de Julio César en el siniestro ni le quita el triste honor de haber sido el primer biblioclasta de Alejandría.

\section{La biblioteca durante los primeros tres siglos de la era occidental}

La biblioteca siguió siendo todavía muy importante durante el período de la administración colonial romana. Sin embargo, este aserto no se ratifica a través del relato del historiador romanizado de origen judío Flavio Josefo (37-100 d. C.), quien omite referirse a cómo era la Biblioteca en su tiempo.

${ }^{1}$ E. M. Forster (1984), Alejandría: Historia y guía. Prólogo de Lawrence Durrell. Barcelona: Seix Barral, pp. 50 y 264.

${ }^{2}$ Plutarco (1983), Vidas Paralelas. Barcelona: Bruguera, p. 211.

${ }^{3}$ Véase Luciano Canfora (1998). La biblioteca desaparecida. Gijón: Ediciones Trea. 
Durante los siglo I y II d. C. la intelectualidad alejandrina pudo desarrollarse y continuar sus actividades a través de sus prestigiosas instituciones. Pero sería en el siglo III d. C. cuando la crisis inevitable que comenzó a resquebrajar los cimientos del imperio proyectó su funesta sombra sobre la hasta entonces apacible vida alejandrina. En 215, el Caracalla (188-217), emperador entre 211-217), un feroz asesino durante su corta existencia, mandó a reprimir una rebelión matando a miles de jóvenes en las calles de Alejandría y destruyendo parcialmente el emblemático Museo.

En 272, luego de la ocupación de Alejandría por Zenobia, la reina de Palmira (antigua ciudad de Siria, situada en un oasis, entre Damasco y el Éufrates, a 140 km de Homs), Aureliano (ca. 214/215-275 d. C.), emperador entre 270-275, destruyó completamente el Bruchión, donde se produjo una masacre ${ }^{4}$. Hacia el final de ese siglo, otra rebelión fue sofocada a sangre y fuego entre diciembre de 297 y marzo de 298 por Diocleciano (244-311), emperador entre 284-311, y muchos alejandrinos fueron brutalmente eliminados 5 .

Después de esta depredación romana, el material salvado de la Bibliotecamadre será trasladado al edificio del Serapeum, en el sur de la ciudad, e integrado a la Biblioteca-hija.

\section{La biblioteca alejandrina y su trágico final}

Durante el siglo IV d. C., luego de la proclamación del cristianismo como la religión oficial del imperio romano, la seguridad de los santuarios griegos comenzó a ser amenazada. Los viejos cristianos de la Tebaida, y los prosélitos, odiaban la Biblioteca porque ésta era, a sus ojos, la ciudadela de la incredulidad, el último reducto de las ciencias paganas. Por esa época parecía impensable que un siglo antes allí hubiera estudiado y formado cientos de discípulos un filósofo racional, y al mismo tiempo muy espiritual, como Plotino (205-270), fundador del neoplatonismo.

La situación se tornó particularmente crítica durante el reinado de Teodosio I (en Oriente entre 379-392), el emperador que no aceptó tomar el título de pontífice máximo y que trató de acabar con las antiguas creencias. Por orden de Teófilo, obispo monofisita de Alejandría, que había peticionado y conseguido un

\footnotetext{
${ }^{4}$ Alaric Watson (2004), Aurelian and the Third Century. London: Routledge, pp. 57-88.

${ }^{5}$ Véase Timothy David Barnes (1982), The New Empire of Diocletian and Constantine. Cambridge, Mass.: Harvard University Press.
} 
Ricardo H. Elía .: El incendio de la biblioteca de Alejandría por los árabes: una historia...

decreto imperial, el Serapeum, el complejo que contenía la preciosa biblioteca y otras dependencias fue destruido y saqueado.

Pablo de Jevenois, el director del área de creación del Instituto Ramón Llul (Cataluña e Islas Baleares, España), nos dice: «Tras el edicto del emperador Teodosio I en el año 391, mandando cerrar los templos paganos, esta magnífica BibliotecaHija pereció a manos de los cristianos en el 391, fecha de la violenta destrucción e incendio del Serapeum alejandrino; las llamas arrasaron allí la última y fabulosa biblioteca de la Antigüedad. Según las Crónicas Alejandrinas, un manuscrito del siglo $V$, fue el Patriarca monofisita de Alejandría, Teófilo (385-412), conocido por su fanático fervor en la demolición de templos paganos, el destructor violento del Serapeum." ${ }^{6}$.

"Ágora” (2009), la película del cineasta chileno Alejandro Amenábar, basada en la biografía de la filósofa y científica alejandrina Hipatia (ca. 370-ca. 415), hija del matemático Theón Alexandricus (ca. 335-405), ilustra con realismo y veracidad los momentos en que la Biblioteca-hija es destruida por los fanáticos monofisitas dirigidos por los fundamentalistas parabolanos que respondían a Teófilo y a su sobrino Cirilo; este último, mejor conocido como San Cirilo (ca. 370-444), sería el instigador del asesinato de Hipatia ${ }^{7}$.

Según el renombrado historiador y teólogo visigodo Paulo Orosio (ca. 383 - ca. 420), discípulo de san Agustín de Hipona (354-430 d. C.), en su Historia contra los paganos (escrita entre 416 y 417), certifica que la Biblioteca alejandrina no existía en 415 d. C.: «sus armarios vacíos de libros... fueron saqueados por hombres de nuestro tiempo» ${ }^{8}$.

El profesor Miguel Castillo Didier después de señalar taxativamente que «... la biblioteca del Serapion fue destruida el año 391 por el patriarca Teófilo.», brinda esta información que completa y certifica nuestras aseveraciones: «...hay que tomar en cuenta que no pocos monumentos habian sido dañados o destruidos por cristianos, incluso antes del edicto de Teodosio, el año 391. Y los que sobrevivieron aún hasta el siglo VII, hasta poco antes de la conquista árabe, fueron demolidos por orden del patriarca jacobita Andrónico hacia el año $620^{9}$."

${ }^{6}$ Pablo de Jevenois (2000), "El fin de la Gran Biblioteca de Alejandría: La leyenda imposible", Revista de Arqueología, Madrid, p. 37.

7 Véase Clelia Martínez Maza (2009), Hipatia: La estremecedora historia de la última gran filósofa de la Antigüedad y la fascinante ciudad de Alejandría. Madrid: La Esfera de los Libros; María Dzielska (2009), Hipatia de Alejandría. Madrid: Siruela.

${ }_{8}^{8}$ Paulus Orosius, Historiarum adversus Paganos, VI, 15, 31.

${ }^{9}$ Miguel Castillo Didier, Alejandría y Kavafis: Ensayo de crónica de una ciudad y su poeta. Santiago: Centro de Estudios Griegos, Bizantinos y Neohelénicos - Facultad de Filosofía y Humanidades - Universidad de Chile, 2007, pp. 32 y 47. 
La desaparición significó la pérdida de aproximadamente el 80\% de la ciencia y la civilización greco-helenística, además de legados importantísimos de culturas asiáticas y africanas, lo cual se tradujo en el estancamiento del progreso científico durante más de cuatrocientos años, hasta que felizmente sería reactivado durante la Edad de Oro del Islam (siglos IX-XII) por sabios de la talla de ar-Razi, alBattani, al-Farabi, Avicena, al-Biruni, al-Haytham, Averroes y tantos otros.

Por otra parte, la otrora capital de los Ptolomeos, que en su momento de mayor apogeo llegó a contar con más de un millón de habitantes, cayó en una franca decadencia debido a las tropelías narradas anteriormente.

\section{La Alejandría musulmana}

A partir de la llegada de los musulmanes, la urbe de Alejandro será paulatinamente remozada alcanzando una gran apogeo en la época de los mamelucos (siglos XIII-XVI d C.). El 17 de septiembre de 642, cuando los musulmanes liderados por Amr Ibn al-Ás ash-Shami (573-663) la conquistaron tras un largo asedio, Alejandría era la capital del Egipto bizantino. A pesar de la admiración que despertó en ellos, no la mantuvieron como tal y fue sustituida por Misr al-Fustat ('Campamento de la tienda'), la ciudad que fundaron como la primera capital del Egipto islámico. La palabra Misr quedó como sinónimo de Egipto y más tarde reemplazó el término griego Aegyptos (los antiguos egipcios llamaban a su país Kemi, "negro").

Sobre el trazado original de Alejandría se asentaron numerosas tribus árabes, con el consiguiente aumento de la actividad constructora y la edificación de mezquitas. El primer gobernador de Egipto, Ibn al-Ás, se ocupó de fortificar las costas expuestas a los ataques navales de Constantinopla (luego de una fugaz reconquista bizantina entre 645-646), y Abd Allah Ibn Sad Ibn Abi as-Sarh (m. 656), segundo gobernador, construyó un astillero en Alejandría.

En la época abbasí, para proteger las zonas pobladas de la ciudad, sobre las ruinas de la muralla antigua, se edificó un nuevo recinto con cuatro puertas que se situaron en los mismos ejes estructurales que las anteriores: al este, la Puerta de Rosetta (Rashíd); al oeste, la Puerta del Loto (Bab Sidra), en la que moría el camino del Magreb; al sur, la Puerta Verde, que no se abría sino el viernes y por ella salían los habitantes a visitar los cementerios; y al norte, la Bab al-Bahr o Puerta del Mar.

Hacia 825-827, unos quince mil musulmanes andalusíes que habían huido de la persecución del emir cordobés al-Hákam I (reinante entre 796-822), 
tomaron Alejandría y luego se adueñaron en su puerto de unos navíos con los que conquistaron a los bizantinos la isla de Creta. Allí fundarían un emirato que perduraría hasta el año 961.

Alejandría recuperó su antiguo florecimiento en la época fatimí (969-1171), período durante el cual resplandeció y participó en muchos de los acontecimientos políticos de Egipto, pues era sede de la flota del califato fatimí. En el año 1013, por orden de Al-Hakim bi-Amr Allah (985-1021), se llevó a cabo el drenaje de su canal para facilitar la navegación entre la ciudad y el Nilo, lo que contribuyó a conectar a Alejandría con el resto de las provincias del país. Entre las mezquitas más famosas de esta época se encuentra la mezquita al-Attarin.

Las fuentes históricas señalan que cuando el sultán Salahuddín al-Ayyubi (1137-1193), el Saladino de los europeos, visitó Alejandría, se interesó por sus defensas y la renovación de su flota, y participó personalmente en la restauración de sus murallas en 1176 .

\section{El mayor puerto del Islam}

Desde la época ayyubí (1171-1250), Alejandría se convirtió en centro del comercio mundial donde se descargaban productos orientales, entre los cuales eran muy apreciados los per-fumes y las especias. El viajero andalusí Ibn Ÿubayr alBalansi (1145-1217) menciona en su Rihla (Libro de viajes) veintiocho ciudades o países que tenían relaciones comerciales con Alejandría, donde cada uno disponía de un funduq (fonda, hospedería) para el alojamiento de sus representantes y el depósito de sus mercancías. Ibn Ÿubayr reconoce: «En primer lugar destaca el hermoso sitio de la ciudad y la vasta extensión de sus construcciones, hasta tal punto que nosotros no hemos visto una ciudad de tan amplias vias, ni de más altos edificios, ni más excelente, ni de mayores multitudes que ésta» ${ }^{10}$.

Alejandría vivió su etapa islámica de mayor prosperidad y alcanzó el apogeo de su actividad en la época de los mamelucos (1250-1517), cuando se convirtió en el puerto marítimo más importante de Egipto y en el mayor centro comercial del mundo islámico de aquel tiempo. Estos hechos coincidieron con la pérdida de importancia de la ciudad de Damietta, al este del delta, por una parte, a los continuos ataques de los cruzados (entre 1217 y 1250), y por otra, a la imposibilidad de navegar por el río, cuya desembocadura se había obstruido, provocando el abandono de esta ruta por los comerciantes.

${ }^{10}$ Ibn Ÿubayr (2007), A través del Oriente: Rihla. Estudio, traducción, notas e índices de Felipe Maíllo Salgado. Madrid: Alianza Editorial, pp. 73-74. 
A pesar de los enormes problemas que amenazaban a su gobierno (invasiones de cruzados y mongoles, subversión ismailí, etc.), Baybars al-Bunduqdari (sultán entre 1260-1277) está considerado el primer soberano mameluco que dedicó especial atención al puerto de Alejandría. Ordenó restaurar sus murallas y construir el puerto de Rosetta, que sería un puesto de observación para controlar el mar. Se preocupó de renovar la flota; ordenó que se la dotase con navíos de guerra y que se talasen los árboles para su construcción.

El sultán an-Nasir Muhammad (que reinó durante tres períodos, entre 1293 y 1340), ordenó que se volviese a excavar y se ensanchase el canal de Alejandría que tenía su origen frente a la ciudad de Fuwa, en el punto donde el Nilo desvía su trayectoria. Este hecho tuvo una gran influencia en el auge del comercio en la época mameluca. Asimismo, ordenó reconstruir el Faro de Alejandría, seriamente dañado por un terremoto en 1303.

Tras el ataque destructor de los cruzados franco-chipriotas acaecido en el año 1365, los sultanes mamelucos reforzaron las fortificaciones de Alejandría para intentar disuadir de sus ambiciones a los invasores europeos. El historiador y geógrafo Abu-l-Fida (latinizado Abulfeda), nacido en 1273 y muerto en 1331, escribió alrededor del año 1300 que Arbuna (Narbona, en el Bajo Languedoc, Francia) fue un importante centro comercial bajo los musulmanes. Por entonces los barcos podían remontar el curso del Aude hasta la ciudad, e incluso llegar más arriba. De ahí partían navíos hacia Alejandría, el mayor puerto del Oriente musulmán, cargados de cobre y estaño procedentes de Toulouse, donde previamente habían descendido la mercancía que traían de Inglaterra, pasando por Burdeos y el Garona [Cfr. Géographie d'Aboulféda. Traducción de Joseph Toussaint Renaud. París: Imprimerie royale, 1848; t. III, p. 307].

\section{El comentario de Ibn Battuta}

Para el gran viajero marroquí Ibn Battuta (1304- ca. 1369/1377), que la visitó en tres oportunidades, en 1326, 1347 y 1349, Alejandría era uno de los puertos más importantes del mundo pero, por sobre todo, una ciudad maravillosa: "En ella hay cuanto quisieras, tanto de hermoso como de inexpugnable, de monumentos pios como profanos. [...] Esta ciudad es una perla resplandeciente y luminosa, una doncella fulgurante con sus aderezos, cuya belleza alumbra el Magreb. Acopia las más variadas hermosuras por su situación intermedia entre Levante y Poniente. Toda maravilla en ella se muestra, al par que reúne cualquier 
Ricardo H. Elía .: El incendio de la biblioteca de Alejandría por los árabes: una historia...

cosa notable. [...] La ciudad posee un puerto grandioso y nunca vi en todos los del mundo otro como él...»" ${ }^{11}$.

\section{Las construcciones de los mamelucos}

Los mamelucos controlaron durante largo tiempo todo el Mediterráneo oriental con una armada que tenía como base el puerto de Alejandría. El sultán al-Ashraf Saifuddín Barsbay (que reinó entre 1422-1438), apodado «la Pantera», con esta poderosa flota lanzó una expedición contra Chipre en 1425 que finalizó con la captura del rey isleño, Jano (g. 1398-1432), cuyo hijo Juan II (g. 14321458) se declaró vasallo del sultán.

Entre las numerosas construcciones realizadas en el período de los mamelucos, sobresale la llamada Ciudadela de Alejandría, o Ciudadela de Qatbay en la rada del puerto, que como su nombre indica, fue erigida por el sultán mameluco Qaitbay, que asumió el poder en el año 1467. Cuando visitó Alejandría y las ruinas del antiguo faro en el año 1477, ordenó construir sobre sus cimientos una burÿ ('torre') a favor de la cual constituyó importantes habices ('donaciones'). Esta Torre de la Ciudadela de Alejandría es similar a la de la Ciudadela de Qaitbay en Rosetta y a la de Ra's al-Nahr en Trípoli, Líbano, construidas todas por el sultán Qaitbay en los mismos años.

Los trabajos duraron dos años, y se gastaron más de cien mil dinares para su construcción. El historiador Muhammad Ibn Iyas (1448-1523), en su obra Bada'i az-Zuhur fi Uaqa'I ad-Duhur [Las hermosas flores acerca de los hechos de los tiempos], que es una Historia sobre Egipto en 6 tomos que finaliza hacia el año 1522, nos indica que la ciudadela estaba dotada de una mezquita comunitaria, una tahona, un horno y un depósito de armas. La ciudadela se edificó sobre una superficie superior a dos faddams (más de $8.400 \mathrm{~m} 2$ ), y para la elevación de los muros se utilizaron enormes bloques de piedra que le dieron su presencia de bella construcción maciza, acorde con su aspecto de fortaleza inexpugnable.

Tras la muerte del sultán al-Ashraf Saifuddín Qaitbay en el año 1496, que coincidió con el descubrimiento por parte de los portugueses de la ruta del Cabo de Buena Esperanza y su consiguiente dominio del comercio con Oriente y ataques a las flotas musulmanas, Alejandría empezó a decaer. Todo ello causó la paralización del comercio, la decadencia de la economía egipcia y,

${ }^{11}$ Ibn Battuta (2005), A través del Islam. Traducción del árabe, introducción y notas de Serafín Fanjul y Federico Arbós. Madrid: Alianza Editorial, pp. 129-130. 
posteriormente, la caída de los mamelucos. De la época otomana en Alejandría se conservan unos pocos vestigios, algunos pequeńos edificios como la mezquita de Ibrahim Tarbana, construida en 1685, y la mezquita de Abd al-Baqi Yurbagui, erigida en 1758 .

\section{Renacimiento}

Luego del período napoleónico (1798-1801) y las invasiones inglesas (18011807), Muhammad Ali (1769-1848), el virrey que entre 1805-1848 logró emancipar a Egipto del Imperio Otomano, que se lo compara con el período de la Revolución Meiji en Japón debido a su tendencia a adoptar la modernización sin menospreciar la tradición. Este gobernante musulmán de origen albanés, construyó el canal de Mahmudiya, abierto en 1847, que unió de nuevo a la urbe alejandrina con el Nilo.

Con el advenimiento del llamado Renacimiento (an-Nahda) cultural árabe, a mediados del siglo XIX, Alejandría se convirtió nuevamente en un centro de florecimiento de la literatura, las artes y las ideas. Incluso, su colectividad griega experimentó un renacer con las letras neohelénicas. Uno de los principales poetas fue Constantino Cavafis (1863-1933), nacido y muerto en Alejandría, una de las figuras literarias más importantes del siglo XX y uno de los mayores exponentes del renacimiento de la lengua griega moderna.

\section{La nueva Biblioteca de Alejandría}

Hoy día, la ciudad de Alejandro, de Cleopatra, de su famoso Faro, de los logros intelectuales de los Ptolomeos y las construcciones de los Mamelucos, sigue destilando su profunda magia como legendaria ciudad de la memoria. La reconstrucción de la antigua gran Biblioteca, fundada por iniciativa de Demetrio de Falero a fines del siglo III a. C., le devuelve su histórica importancia.

Inaugurada el 31 de diciembre de 1996, tiene una superficie de 36.770 metros cuadrados con una altura de 33 metros. Consta de once niveles, de los cuales cuatro se hallan por debajo del nivel de la calle. Se ha calculado que el número posible de libros puede llegar a los veinte millones; de momento dispone de unos 200.000; la mayoría de ellos son donaciones. Hay 50.000 mapas, 10.000 manuscritos, 50.000 libros únicos y además ejemplares del mundo moderno, con 10.000 multimedia de audio y 50.000 multimedia visuales. Todo esto lo rigen y supervisan unos 600 funcionarios. 
Ricardo H. Elía .: El incendio de la biblioteca de Alejandría por los árabes: una historia...

\section{El primer inventor de la leyenda}

Abdul Latif al-Bagdadi (ca. 1160-1231) fue un personaje muy contradictorio en la historia islámica. Aunque buen alquimista y médico, donde hizo agua fue como historiador. Parece ser que se traumatizó con la antigua historia de Egipto y él fue el inventor del mito del incendio de la Biblioteca de Alejandría por los musulmanes. Hacia 597 y 598 AH (1201/1202) escribió el Kitab al-ifada wa al-ítibar fi al-umur al mushahada ua al-hawadiz al-mu'ayana bi-ard Misr (Tratado de la utilidad y la consideración sobre los asuntos testimoniados y los acontecimientos observados en la tierra de Egipto), que combina elementos de alquimia y botánica con datos históricos, geográficos y culturales ${ }^{12}$.

En esta obra, Abdul Latif sin esgrimir prueba alguna, hace responsable a Omar Bin Al-Jattab por la supuesta acción de Amr Ibn al-Ás. Para ser que este autor iraquí estuvo embargado por el fanatismo ismailíi ${ }^{13}$ y una tendencia a endilgarle al califa Omar todos los males del mundo.

El profesor Mustafá El-Abbadi, doctorado en la Universidad de Cambridge y director de la Nueva Biblioteca de Alejandría, es el especialista que ha analizado concienzudamente los pormenores de la invención, esclareciendo acabadamente sobre los personajes y móviles que la fraguaron: "En el año 642, el general árabe Amr conquistó Egipto y ocupó Alejandría. Los acontecimientos del comienzo de la conquista árabe han sido relatados por historiadores de ambos bandos, tantos árabes como coptos y bizantinos. Sin embargo, durante más de cinco siglos después de la

${ }^{12}$ Hay una versión árabe de la Imprenta del Valle del Nilo, Egipto, 1276 AH, o sea: 1859. La versión francesa se realizó durante la época napoleónica y correspondió al famoso arabista Silvestre de Sacy (1758-1838), Abd-Allatif (1810), Relation de l'Égypte. Le tout traduit et enrichi de notes historiques par Silvestre de Sacy. Paris: Imprimerie Impériale. Fue traducido al inglés en los años sesenta del pasado siglo como Abd al-Latif (1965), The Easternf key:Kitab al-ifadah wal-itibâr / of 'Abd al-Latif al-Baghdadi. Translated in English by Kamal Hafuth Zand, and John A. and Ivy E. Videan. London: Allen and Unwin.

${ }^{13}$ El ismailismo es una herejía del Islam. Surgió en el siglo VIII a través de los llamados shiíes septimanos, seguidores de Ismail (719/722 - 762/775), hijo de Ÿafar as-Sadiq (702-765). A partir de entonces este movimiento conformará variantes sincréticas como los cármatas, fatimíes, nizaríes y drusos. En su doctrina caben concepciones como la trinidad, metempsicosis y reencarnación. Los nizaríes dieron origen a dos grupos terroristas (uno con base en Masyaf, Siria, y el otro en Alamut, Irán) que fueron conocidos en árabe hashashiyyún ("adictos al hachís"). Esta denominación originó el término «Asesinos» popularizado por Marco Polo (1997), Libro de las Maravillas. Barcelona: Ediciones B, pp. 93-99. Esto se explica por el hecho de que los comandos de Masyaf y Alamut -que difundían el terror asesinando a dirigentes musulmanes sunníes y shiíes opuestos a sus ideas-, consumían drogas psicoactivas derivadas del opio antes de ejecutar su misión. 
conquista no se puede encontrar ninguna referencia a una biblioteca de Alejandría bajo la dominación árabe. De repente, a principios del siglo XIII, encontramos un relato en el que se describe cómo Amr habia quemado los libros de la antigua biblioteca de Alejandría. Los primeros informes de tal acontecimiento están registrados por dos escritores árabes: Abdul Latif de Bagdad e Ibn Al-Qifti. El mencionado en primer término fue un distinguido médico que residió en Siria y Egipto hacia el 1200 (565 de la Hégira). A raiz de su visita a Alejandría cuenta en un texto confuso que vio el gran pilar (normalmente llamado el Pilar de Pompeyo), alrededor del cual se encontraban otras columnas. Entonces añade una opinión personal: "Creo - dice-que se trataba del emplazamiento del pórtico donde Aristóteles y sus sucesores impartían sus enseñanzas; era el centro de estudio creado por Alejandro cuando fundó la ciudad; ahi se encontraba el almacén de libros que fue incendiado por Amr, por orden del califa Omar VViaje a Egipto, Ifada wa I'tibar]. Es evidente que lo que Abdul Latif dice a propósito de Aristóteles y Alejandro es incorrecto; el resto de sus afirmaciones acerca del incendio del depósito de libros no está documentado y por lo tanto no tiene valor histórico» ${ }^{14}$.

La versión de que Aristóteles enseñaba en el ágora de Alejandría es un disparate mayúsculo y habla por sí sola sobre que Abdul Latif no es un historiador confiable. El Estagirita nunca salió de Grecia y murió en el 322 a. C. Alejandría que había sido fundada por Alejandro diez años antes, en 332, estaba en construcción y ni el ágora ni la biblioteca existían. Por otro lado, Alejandro no vería ningún edificio pues partió rápidamente hacia el oasis de Siwa para luego continuar con su expedición al Asia Central y la India.

\section{El primer transmisor de la leyenda}

La clave de esta fábula es, sin embargo, Abu-l-Hasan Ali Yusuf Ibn al-Qifti (1172-1248), originario de la pequeña población de al-Qift, la antigua Coptos, al norte de Luxor, en el Alto Egipto. De su principal trabajo, Ijbar ul-Ulamá (Información de los Sabios), Muhammad Ibn Ali al-Zauzani, bajo el título de Tarij ul-Hukamá (Historia de los Entendidos), realizó un extracto en 1249 donde aparece la leyenda de al-Qifti. Éste cita a un sacerdote copto alejandrino llamado Juan Filopón, también conocido como Juan el Gramático, que pidió permiso para leer los libros de la Biblioteca de Alejandría a un general árabe llamado Amr, quien no quiso concedérselo sin consultar al califa Omar. Ésta fue su respuesta: «Si los libros contienen la misma doctrina que el Corán, no sirven de nada

${ }^{14}$ Mustafá El-Abbadi (1999), La Antigua Biblioteca de Alejandría: Vida y destino. París-Madrid: Unesco, pp. 184-185. 
porque repiten; si no están de acuerdo con la doctrina del Corán, no tiene sentido conservarlos». Según atestigua al-Qifti, por orden del califa, "los rollos se habrían quemado a lo largo de seis meses para calentar los baños públicos".

Ibn al-Qifti comete una acronía al ubicar a Juan el Gramático a mediados del siglo VII. Éste, también llamado Juan Filopón (Philoponos), había sido un filósofo y gramático griego cristiano que vivió entre 490 y 566 y que jamás pudo estar con vida en Alejandría en 642.

El profesor El-Abbadi igualmente refuta fácilmente esta serie de absurdos: "Ibn Al-Qifti identifica a Juan el Gramático con Juan Filopón, quien escribió contra el credo nestoriano bajo Justiniano, alrededor de 540; por lo tanto, hubiera sido imposible que pudiera sobrevivir y estar activo cien años después en el tiempo de la conquista árabe. Desde el siglo IV los libros fueron habitualmente escritos sobre pergamino, el cual no es apropiado para quemar. El método económico de quemar los libros para calentar baños públicos, pone en evidencia la naturaleza ficticia de toda la historieta.» ${ }^{15}$.

Analicemos hasta qué punto son absurdos los argumentos de esta leyenda. Ibn al-Qifti en su versión pretende que el número de los baños que fueron calentados por los volúmenes de la biblioteca eran cuatro mil. Por consiguiente, si se hubieran destruido veinte volúmenes solamente por baño y por día, el total luego de seis meses sería de 14 millones cuatrocientos mil volúmenes. Ahora bien, si los baños de Oriente tenían piscinas de agua caliente a sesenta grados, es totalmente imposible que veinte volúmenes puedan dar el número necesario de calorías; y si tenemos que multiplicar por cinco, como ejemplo, el número de volúmenes de cada baño, se pasará al límite del desatino. Tengamos presente que el número mayor de volúmenes (en realidad de rollos) que albergó la biblioteca alejandrina fue de setecientos mil, y es probable que ésa sea incluso una cifra un poco exagerada.

Ahora veamos el resto de la investigación del profesor El-Abbadi sobre Ibn alQifti que nos conducirá a una insospechada conclusión: «Primeramente, el pasaje relativo a Juan el Gramático esta extraido casi literalmente de la obra de Ibn Nadim [que vivió en Bagdad entre 936-c.995/998, autor del famoso Kitab al-Fihrist, 'El Libro de los índices']... Es significativo que Al-Nadim hubiera consignado todos los detalles tomados por Al-Qifti sobre la vida de Juan el Gramático, incluyendo su relación con Amr; pero no menciona la conversación sobre la biblioteca... en cuanto al pasaje relativo al divertido intercambio de mensajes entre Amr y el califa, y el

${ }^{15}$ M. El Abbadi: 1994, pp. 170-171. 
modo tan utilitario de emplear los libros para calentar los baños, no se encuentra en ninguna fuente más antigua. Esto muestra que, hasta el siglo XII, los escritores árabes y bizantinos se interesaban por la Biblioteca de Alejandría y su historia, pero ninguno de ellos tenía constancia de que hubiera sobrevivido hasta la conquista árabe. Es, por lo tanto, razonable pensar que sólo el tercer pasaje, el que se refiere a los libros arrojados al fuego por Amr, es una invención correspondiente al siglo XII (siglo VII de la Hégira)» ${ }^{16}$.

Después de Ibn Al-Qifti, otros autores árabes, cristianos y musulmanes, repitieron estas imposturas, a veces en su versión completa, a veces de forma abreviada. Para redondear, dice el profesor El Abbadi: "A partir del siglo IV los libros solian ir escritos sobre pergamino, que no arde. El móvil del uso económico, consistente en quemar los libros para calentar los baños públicos, revela el carácter ficticio de toda la historia.» ${ }^{17}$.

\section{El segundo transmisor de la leyenda}

La versión de Ibn Al-Qifti fue reivindicada por otro impostor que aportó su propia versión de los hechos. Se trata de Iuhanna Abu al-Faraÿ Ibn al-Ibri (12261289), latinizado Abulfaragius Bar Hebraeus ('el hijo del hebreo'). Éste fue hijo de un médico judío, Aarón de Malatia (hoy Turquía), que se hizo cristiano. En 1264 fue nombrado mafrián, arzobispo de los jacobitas orientales. Su asiento estaba en Mosul (Irak), sin embargo, habitaba las ciudades iranias de Tabriz y Maragha, donde residían los Ilhanes mogoles. Bar Hebraeus es autor de una voluminosa obra de la Historia de Siria, país donde residió largo tiempo, y otra conocida en Occidente como "Historias o Compendio de Dinastías de los Árabes". Su obra, incongruente y contradictoria, no es para nada confiable.

Los historiadores europeos de los siglos XVII y XVIII especializados en temas árabes e islámicos como Gibbon, Ocley, Gagnier, Boulainvilliers o Niebuhr sólo tomaron en cuenta sus descripciones geográficas y culturales, obviando sus comentarios sobre los hechos políticos, por lo general insubstanciales e indocumentados.

Los modernos investigadores señalan a este conspicuo representante monofisita como uno de los propagadores principales del mito de la quema de la biblioteca alejandrina por los musulmanes, que sirvió durante cierto tiempo

${ }^{16}$ M. El-Abbadi: 1999, p. 185.

${ }^{17}$ M. El-Abbadi: 1999, p. 186. 
para echar una columna de humo sobre la identidad del verdadero responsable, su correligionario Teófilo del siglo IV.

El hecho es que se trata de una invención tardía, con fines de desprestigio político, tejida en el siglo XIII, 600 años más tarde de la conquista musulmana de Egipto y en plenas Cruzadas. Su súbita aparición coincide con la breve conquista de Alejandría y Egipto por San Luis IX (1249-50), en la VII Cruzada, lo que despertaría el interés por la ciudad legendaria y reavivaría la memoria de la pavorosa destrucción por los cristianos monofisitas de la Biblioteca-Hija de Alejandría, la última gran biblioteca de la Antigüedad. El mismo siglo XIII que vio además a los últimos cruzados abandonar el Medio Oriente, tras el fracaso de las séptima y octava Cruzadas y las victorias de Ruknuddín Baibars al-Bunduqdari, sultán mameluco de Egipto y Siria (1260-1277).

«Ibn al-Ibri inserta su 'Specimen Historiae Arabum', dentro de su obra más famosa, 'Chronicon Syriacum', que es una historia universal desde Adán hasta su tiempo, escrita en siríaco, con un resumen en árabe. El relato finaliza acusando al general Amr de haber quemado entonces los miles de libros de la famosa Biblioteca de Alejandría por orden del califa Omar, "haciéndole a él y a su pueblo responsable ante la Historia de semejante hecatombe cultural". Asi nació la versión imposible de la leyenda, a fines del medievo, en el siglo XIII. [...] Esta singular afirmación de Abulfaragius es un hapax legomenon, apareciendo una sola vez en todo el medievo. Incluso única en su género, provocaría la difusión en Occidente de la famosa leyenda atribuyendo el incendio de la Gran Biblioteca a sus más encarnizados enemigos de la época, a la religión rival monoteista que llegaba triunfante del fondo del desierto arábigo. Tal afirmación jamás pudo salir de escritores medievales árabes, conscientes de su papel fundamental en la transmisión de los textos clásicos a Occidente, que ya se estudiaban gracias a ellos en Chartres, Bolonia, Oxford y París. La misma contrasta con el absoluto silencio de más de quinientos años de los autores que antes de Abulfaragius hablaron de la conquista árabe de Alejandría, tanto árabes, como coptos y bizantinos ${ }^{18}$.

\section{La refutación de los investigadores}

El primero de los investigadores que demostrará la falsedad de las aseveraciones de Ibn al-Ibri fue el teólogo y orientalista francés Eusèbe Renaudot (1646-1720) en 1713 al traducir al latín la "Historia de los Patriarcas de Alejandría"19, una obra de la Iglesia Ortodoxa Copta compilada por varios autores entre los siglos X y XII.

${ }^{18}$ M. El-Abbadi: 1999, pp. 186-187. 
Edward Gibbon (1737-1794), el famoso historiador británico, en su obra por excelencia coincide con lo antes expuesto y nos brinda este testimonio: "Como las Dinastias de Abulfarach han cundido en una traducción latina, se ha ido repitiendo la patraña, y todos los eruditos están llorando airadamente aquel malogro y naufragio literario de los tesoros de la antigüedad [...] El fallo tremendo de Omar se contrapone al precepto castizo y fundamental de los moralistas Musulmanes quienes pregonan expresamente que los libros religiosos de Judios y Cristianos, deparados por el derecho de guerra, jamás deben arrojarse a las llamas, y que los libros profanos de historiadores o poetas, de médicos y filósofos, pueden ser provechosamente valorados por los fieles» ${ }^{20}$.

Gustavo Le Bon (1841-1931), el orientalista francés, añade que «Amru se mostró indulgente con los habitantes de la gran ciudad, y no sólo les evitó todo acto de violencia sino que procuró ganarse su voluntad, escuchando todas sus reclamaciones y procurando satisfacerlas. En cuanto al pretendido incendio de la biblioteca de Alejandría, semejante vandalismo eran tan impropio de las costumbres de los árabes, que cabe preguntarse cómo tan disparatada leyenda ha podido hallar crédito durante tanto tiempo entre muchos escritores formales [...] Ha sido facilísimo demostrar por medio de citas muy claras, que muchos antes de los árabes, los cristianos habian destruido los libros paganos de Alejandría con el mismo tesón con que habian destruido las estatuas, y por consiguiente que Amru no quemó ni halló libros que quemans ${ }^{21}$.

Alfred Joshua Butler (1850-1936), historiador británico de Oxford especializado en el Egipto copto, brinda este testimonio en su trabajo sobre la Conquista árabe del país del Nilo publicado por primera vez en 1902: «Tomemos un caso particular. Ya he contado la visita de Juan Mosco y su amigo Sofronio a Egipto, no muchos años antes de la conquista árabe, y he demostrado el gran interés intelectual de los dos eruditos y su afición por todo aquello que tuviese la forma de un libro: pero aunque ambos fueron escritores muy prolificos, y viajaron y residieron mucho tiempo en Egipto, en sus páginas se buscará en vano cualquier alusión en el pais a otra cosa que no fueran bibliotecas privadas. Dos siglos de silencio, terminando

${ }^{19}$ VV.AA. (1713). Historia patriarcharum alexandrinorum jacobitarum. Paris: Franciscum Fournier. ${ }^{20}$ E. Gibbon (1984), Historia de la Decadencia y Ruina del Imperio Romano. Madrid: Ediciones Turner; Tomo VI, Aparición del Islam. Años 412 a 1055, Capítulo LI, pp. 326-327.

${ }^{21}$ G. Le Bon (1974), La Civilización de los Árabes. Buenos Aires: Editorial Arábigo-Argentina "El Nilo”; Capítulo IV, p. 193. 
Ricardo H. Elía .: El incendio de la biblioteca de Alejandría por los árabes: una historia...

en el silencio de Juan Mosco $^{22}$ y Sofronio ${ }^{23}$, torna inverosimil que pueda haber existido una gran biblioteca pública cuando los árabes entraron en Alejandria» ${ }^{24}$.

El bibliotecario español Hipólito Escolar Sobrino (1919-2009) esgrime esta hipótesis: "La leyenda muy bien pudo nacer de la necesidad de explicar la desaparición de la biblioteca, cuya existencia se conoció más tarde en el mundo musulmán cuando se tradujeron las obras de los grandes filósofos y cientificos griegos al árabe» ${ }^{25}$.

"La leyenda, sesgada y falsa, ignora completamente la afirmación del obispo de Constancia y padre de la Iglesia, Epiphanios (315-403), en su 'Patrología Graeca', quien afirmaba que "... el lugar de Alejandría donde una vez estuvo la Biblioteca, ahora es un páramo". [...] Por tanto, la leyenda es, efectivamente, una fábula inventada, un engaño imposible que no resiste ni un somero análisis crítico. Los árabes nunca incendiaron la Gran Biblioteca de Alejandria; sencillamente porque, cuando llegaron en el siglo VII, ya hacia cientos de años que no existía» ${ }^{26}$.

El conocido arabista, islamólogo y turcólogo británico judío Bernard Lewis (nacido en 1916) redactó especialmente un artículo donde señala este hecho crucial: "Para aceptar la historia de la destrucción árabe de la biblioteca de Alejandria, hay que explicar cómo es posible que un evento tan dramático no fuese mencionado y pasase inadvertido, no sólo en la rica literatura histórica del Islam medieval, sino incluso en las literaturas de los coptos y otras iglesias cristianas, de los bizantinos, de los judios, o cualquier otra persona que podría haber pensado que la destrucción de una gran biblioteca es digna de comentario. Que la historia aún sobreviva, y se repita, a pesar de todas estas objeciones, es testimonio del poder perdurable de un mit, ${ }^{27}$.

Asimismo, Mostafa El-Abbadi en una nueva obra llamada ¿Qué le sucedió a la antigua biblioteca de Alejandría? cita los nombres de diversos especialistas que desde principios del siglo XX refutaron el mito del incendio de la biblioteca alejandrina por los árabes. Entre ellos, menciona a Victor Chauvin (1844-1913),

22 Juan Mosco (ca. 550 - ca. 634), apodado El Abstemio, fue un monje ciliciano autor de obras hagiográficas sobre los padres del desierto y sobre san Juan el Limosnero o Juan V de Alejandría (m- 619).

${ }^{23}$ Sofronio I de Jerusalén (ca. 556 - 638), patriarca de Jerusalén y santo de la Iglesia quien firmó un convenio de amistad y entendimiento con el califa Omar Bin Al-Jattab cuando éste entró en la capital de Palestina en febrero de 638.

${ }^{24}$ A. J. Butler (1978), The Arab Conquest of Egypt and the Last Thirty Years of the Roman Dominion. Oxford: Oxford University Press, pp. 423-427.

${ }^{25}$ Hipólito Escolar Sobrino (2001), La Biblioteca de Alejandría. Madrid: Gredos, pp. 123-124.

${ }^{26}$ Pablo de Jevenois: 2000, pp. 27-28.

${ }^{27}$ Bernard Lewis (1990). “The Vanished Library”. The New York Review of Books. 37 (14). 
un profesor de árabe y hebreo de la Universidad de Lieja que en su estudio "El libro en el mundo árabe" ${ }^{28}$ hace una demolición del mito del incendio de la biblioteca de Alejandría por los musulmanes ${ }^{29}$.

Por último cabe citar al historiador copto Juan de Nikiu, obispo de Nikiu Pashati en el Delta del Nilo, y que fue administrador de monasterios en el Alto Egipto hacia 696. Fue autor de una historia universal desde Adán hasta el fin de la conquista musulmana de Egipto. Juan, que por cierto no puede decirse que simpatizaba con los musulmanes, no menciona absolutamente nada sobre destrucciones hechas por éstos en Egipto ni en ninguna otra parte. Existen claros testimonios de que tanto Juan como el pontífice copto de Alejandría, Benjamín I (590-661), mantuvieron buenas relaciones con el conquistador Amr Ibn-al-Ás.De esto da buena fe el historiador británico Hugh Kennedy (arabista e islamólogo de Cambridge) que comenta sobre el particular: "Ya hemos visto el modo en que el biógrafo de Benjamín describe las buenas relaciones entre Amr y su héroe, pero el veredicto de Juan de Nikiu es aún más sorprendente. Juan no era un admirador del gobierno musulmán y fue ardiente en su denuncia de lo que consideraba opresión y abuso. No obstante, he aqui lo que dice a propósito de Amr: "Exigía el pago de los impuestos que habian sido acordados, pero no se apoderó de ninguna de las propiedades de las iglesias, y no cometió ningún expolio o saqueo, y las preservó durante todos sus dias” 30 " ${ }^{31}$.

\section{Los musulmanes fueron y son bibliófilos por tradición}

Es sabido entre los hombres de ciencia y erudición que los musulmanes siempre han mostrado por los libros el mayor de los respetos y los cuidados. Siempre estuvieron más orgullosos de sus bibliotecas y librerías que de sus armas, palacios y jardines. Durante el siglo X, en la Alta Edad Media, cuando los castillos de los príncipes cristianos tenían bibliotecas de diez volúmenes, mientras no excedían de treinta a cuarenta las de los monasterios más famosos por su

${ }^{28}$ Victor Chauvin (1911), Le Livre dans le monde arabe. Brussels: Goosens.

${ }^{29}$ Mostafa El-Abbadi and Omnia Mounir Fathallah (Editors) (2008), What Happened to the Ancient Library of Alexandria? Ismail Serageldin (Introduction). Leiden: Brill Academic Publishers, p. 214.

${ }^{30}$ John (Bishop of Nikiu) (1916), The Chronicle of John (c. 690 AD) Coptic Bishop of Nikiu: Being a History of Egypt Before and During the Arab Conquest. Trans. by Robert Henry Charles. London: Philo Press, p. 200.

${ }^{31}$ Hugh Kennedy (2007), Las grandes conquistas árabes. Traducción castellana de Luis Noriega. Barcelona: Editorial Crítica, p. 193. 
ciencia, como Cluny o Canterbury, la de los califas de Córdoba alcanzaban los cuatrocientos mil.

"Cuando los árabes, inspirados por las enseñanzas de Mahoma, salieron del desierto en el siglo VII, no tenían literatura excepto el Corán. En el curso de trescientos años, las bibliotecas musulmanas se extendieron desde España hasta la India por tierras que habian sido parte de los imperios romano, bizantino y persa. Contrariamente a muchos pueblos conquistadores, los árabes tenian gran respeto por las civilizaciones que conquistaban. Consideraban fuente de inspiración el conocimiento de los griegos, los persas y los judios. Cuando el poeta al-Mutannabi proclamó que "el asiento más honorable de este mundo es la montura de un caballo", agregó que "el mejor compañero siempre será un libro". [...] Influenciados por las antiguas tradiciones literarias de Bizancio y Persia, los árabes estudiaron las ciencias filosóficas: medicina, astronomía, geometría y filosofía. Al principio traducían trabajos antiguos, pero los musulmanes, que poseían el conocimiento sagrado, pronto contribuyeron prolificamente a la literatura cientifica. A través de sus trabajos la Europa cristiana recibió la inspiración para su Renacimiento» ${ }^{32}$.

Igualmente, el enciclopedista Abu al-Hasan Ali Al-Mas’udi (ca. 896-956), llamado el Herodoto árabe, hacia 947 afirma en su obra cumbre: "La historia cautiva el oido del sabio y el del ignorante; el simple y el inteligente se encantan con sus relatos y los solicitan. La historia comprende todas clases de temas. Su superioridad sobre las otras ciencias es evidente, y todos los ingenios le conceden la supremacía. Con razón dicen los sabios que el amigo más seguro es un libro»" ${ }^{33}$.

\section{La Casa de la Sabiduría}

Un hecho altamente decisivo para el desarrollo de la civilización islámica fue la fundación por parte de al-Mamún (786-833), hijo de Harún ar-Rashíd y séptimo califa abbasí (813-833), de la "Casa de la Sabiduría" (Bait al-Hikma) en Bagdad hacia 832. Esta institución, financiada por el erario público (Baitul Mal), se destinó a la traducción de manuscritos griegos, helenísticos, y también persas, siríacos y sánscritos, que versaban sobre ciencias antiguas, especialmente filosofía y ciencias naturales.

${ }^{32}$ Fred Lerner (1999), Historias de las bibliotecas del mundo. Desde la invención de la escritura hasta la era de la computación. Buenos Aires: Editorial Troquel; Capítulo V: Bibliotecas del mundo islámico, p. 85.

${ }^{33}$ El-Mas'tudits Historical Encyclopaedia V1: Entitled Meadows of Gold and Mines of Gems, -Muruj adh-dhahab wa matadin al-jawhar-(1841/2010), ["Las praderas de oro y gemas preciosas"], Aloys Sprenger (1813-1893), Translator. Kessinger Publishing, Whitefish, Montana, p. 30. 
Al-Mamún reclutó a los hombres más talentosos para la Casa de la Sabiduría y eligió entre ellos a los Banu Musa, al matemático al Juarizmi, al filósofo y musicólogo al-Kindi y al traductor al-Hä̈ÿä Ibn Yusuf Ibn Matar.

Abu Zayd Hunayn Ibn Ishaq al-Ibadi (808-873), un asirio conocido entre los latinos como Johannitius, hijo de un farmacéutico nestoriano de Hira (Irak), sería el más importante y trascendente traductor del griego al árabe de su tiempo. La mayoría de los traductores de la siguiente generación recibirían entrenamiento de Ibn Ishaq o de sus discípulos. Igualmente, sería el primer director de la casa de la Sabiduría con apenas 24 años.

Hunayn que estudió medicina con el distinguido médico Ibn Masawaiyh (777-857), (a su vez discípulo del famoso médico de Gundishapur, Irán, Ÿibril Ibn Bajtishu), era bilingüe desde la infancia pues hablaba siríaco y árabe. De joven fue a "la tierra de los griegos" (quizás Alejandría o Constantinopla), donde adquirió un completo dominio del griego. Habiendo vuelto a Bagdad, llamó la atención de un miembro de la familia Bajtishu y de los hermanos Banu Musa.

Hunayn mismo nos informa que al-Mamún pagaba las obras traducidas según su peso: si un libro pesaba una libra el traductor recibía una libra de oro. Con sus traducciones de textos galénicos e hipocráticos Ibn Ishaq colaboró de una manera decisiva en la transmisión del saber científico helénico al Islam. Es autor también de los primeros tratados árabes de oftalmología.

Muchas de las traducciones de Hunayn Ibn Ishaq eran esfuerzos de colaboración. Por ejemplo, Hunayn podía traducir una obra griega al siríaco, y a continuación su sobrino Hubaysh pasaba el texto al árabe. El hijo de Hunayn Ibn Ishaq, Ishaq Ibn Hunayn (ca. 830-ca. 911), traducía del griego al siríaco o al árabe, y además hacía revisiones de las traducciones de sus colegas. Y Hunayn, además de hacer sus propias traducciones del griego al siríaco o al árabe, parece haber insistido en comprobar las traducciones de sus discípulos.

Hunayn y sus colaboradores eran extremadamente sofisticados en sus métodos. Comprendieron la necesidad de comparar los manuscritos siempre que era posible, con el fin de descartar errores. Y en lugar de seguir la práctica común en la traducción de la sustitución mecánica de palabra por palabra (que adolece del grave inconveniente de no toda palabra griega tiene su contrapartida en árabe o en siríaco, a la vez que falla también al no tomar en cuenta las diferencias sintácticas entre las lenguas), Hunayn comprendía el significado previo de un 
enunciado en el original griego y lo traducía mediante un enunciado árabe o siríaco de significado equivalente.

El grueso de las traducciones de Hunayn fue de obras medicina, con especial énfasis en Galeno e Hipócrates. Tradujo alrededor de noventa obras de Galeno del griego al siríaco y unas cuarenta del griego al árabe: de Hipócrates, unas quince obras. También tradujo (o corrigió) tres diálogos de Platón, incluido el Timeo, varias obras de Aristóteles (en la mayoría de los casos del griego al siríaco), incluidas la Metafísica, Acerca del alma, Sobre la generación y la corrupción y parte de la Física, distintas obras de lógica, matemáticas y astrología y elaboró una versión siríaca del Nuevo Testamento.

Thabit Ibn Qurra al-Harrani (836-901) es otro gran traductor y cien-tífico de la Casa de la Sabiduría, pero totalmente atípico: no era ni cristiano ni musulmán sino miembro de la secta de los sabeos de Harrãn (Siria). Hablaba fluidamente el árabe, el siríaco y el griego. Thabit tradujo una gran cantidad de tratados matemáticos y astronómicos griegos.

Él mismo famoso matemático es autor de un teorema que sería demostrado por el matemático y físico persa Kamaluddín Abu al-Hasan al-Farisi (muerto hacia 1320). Además realizó estudios en trigonometría esférica, geometría analítica y geometría no euclideana. En astronomía Thabit fue el primero de los re-formadores del sistema ptolemaico y en mecánica fue el fundador de la estática. Thabit declara que Euclides y Nicómaco estudiaron números perfectos y que Euclides dio un código para determinarlos.

El hecho de que tanto cristianos, judíos y paganos trabajaran con sus colegas musulmanes en una importante institución como la Casa de la Sabiduría habla a las claras del grado de convivencia que existió durante la época del Islam clásico.

\section{Las bibliotecas fatimíes}

Los califas de la dinastía fatimí, que gobernaron (909-1171) en el norte de África, Egipto y Palestina, fundaron en 969 la ciudad de El Cairo, y en 970 la Universidad de Al-Azhar ('la Resplandeciente', llamada así en honor y memoria de la hija del Profeta del Islam, Fátima az-Zahra, que vivió entre 605-632,

También crearon espléndidas bibliotecas y dotaron con generosidad a las de muchas mezquitas. La Biblioteca de palacio en tiempos del quinto califa fatimí, Abu Mansur Nizar al-Aziz Billah (975-996), fue llamada Dar al-Ilm ('Puerta del Conocimiento'). Su bibliotecario, Ali Ibn Muhammad al-Shabushti, que conversaba con el soberano de asuntos literarios, había distribuido los fondos, 
de acuerdo con su materia, en cuarenta habitaciones. Disponía de riquísimos Coranes y de dieciocho mil obras helenísticas sobre ciencias naturales y filosofía. Estaba financiada en parte por los recursos del Estado y en ella estaban representados todos los dominios del saber.

A los lectores se les proporcionaba pluma, papel y tinta, y los bibliotecarios y los investigadores ¡percibían incluso un salario! El califa fatimí al-Hákim (que gobernó entre 996-1021) le añadió una academia en 1005.

\section{Las bibliotecas de Asia central}

Entre los siglos XI y XV se crearon numerosas bibliotecas en el Oriente musulmán. El sabio persa Nizam al-Mulk (1018-1092), autor del Seyasak Nameh ("Libro del gobierno") y visir de los sultanes selÿukíes Alp Arslān (1063-72) y Malik-e Shah (1072-92), fundó una célebre madrasa (universidad teológica) y biblioteca en Bagdad en 1064 que recibiría la denominación de Nizamiyya en su honor. En 1234, el califa abbasí al-Mustansir transfirió una parte de sus libros, ochenta mil volúmenes, a la madrasa al-Mustansiriyya, que él mismo había fundado en Bagdad.

Yakut Abdillah ar-Rumi (1179-1229) fue junto al-Idrisi (1099-1166), uno de los más grandes geógrafos musulmanes. Griego del Asia Menor, donde había nacido, fue educado por un mercader de Bagdad y gracias a su buen trato y orientación se convirtió al Islam. Viajó mucho, primero como mercader, luego como geógrafo e historiador. En Merv (una ciudad-oasis en la actual República de Turkmenistán, hoy desaparecida) encontró diez bibliotecas, una de ellas con doce mil libros. Los bibliotecarios, que sabían distinguir quien amaba la sabiduría, le permitieron llevar hasta 200 volúmenes de una vez a su aposento.

El sultán Ulug Beg (1394-1449), nieto del conquistador Tamerlán (13361405), escritor y astrónomo, construyó un célebre observatorio en Samarcanda dotado de una gran biblioteca. Finalmente, debemos mencionar las bibliotecas otomanas que fueron muchas y riquísimas.

Una de las más célebres es aquella que se encuentra en el centro del tercer patio del Palacio de Topkapi en Estambul, contigua a la Sala de Audiencias: la biblioteca de Ahmet III, el sultán que gobernó durante la llamada 'Era de los Tulipanes'. Es un bellísimo edificio construido enteramente en mármol blanco en 1719 rodeado de naranjos y cipreses al que se sube por una doble escalinata. La biblioteca fue levantada sobre un elevado basamento para aislarla de la humedad 
tan frecuente que genera el Bósforo. Guarda más de cuatro mil manuscritos, mayoritariamente islámicos y únicos en su género.

\section{La biblioteca personal de un caballero musulmán}

Abu 1-Mudaffar Usama Ibn Murshid Ibn Alí Ibn Múnqidh (1095-1188), un famoso caballero sirio, autor de obras de poesía, retórica, historia y religión, además de su 'Autobiografía'34, es el ejemplo de muchos musulmanes de la época que disponían privadamente de gigantescas bibliotecas, algo que ningún príncipe europeo contemporáneo jamás imaginó poseer ya que en su mayoría eran analfabetos y no sabían ni leer ni escribir.

Mustafá El-Abbadi cita un episodio que involucró a Usama (en árabe, "cachorro de león") y lo marcó por siempre: "Otro acontecimiento de menor importancia indica lo que podía llegar a ocurrir en esos tiempos turbulentos (de las Cruzadas). Osama Ibn Munquidh, un célebre general y poeta musulmán, habia conseguido un salvoconducto del rey de Jerusalén que le permitía a él y a su familia dirigirse por mar desde Egipto a Siria, pero ante San Juan de Acre unos cruzados, soldados del rey, detuvieron el barco y confiscaron todos sus bienes, incluida su biblioteca, compuesta por 4.000 magnificos libros, lo cual 'dejó en mi corazón una herida que no cicatrizará mientras viva» ${ }^{35}$.

\section{Las bibliotecas de la España musulmana}

En al-Ándalus, la España la arabización fue fácil y rápida y pronto la nueva cultura desplazó a la latina, tanto en el campo literario como en el científico. Este avance cultural se vio favorecido por la aparición de bibliotecas y entre ellas destacaron las de algunos de los emires omeyas, como Abd ar-Rahmãn II (822852), Muhammad I (852-886), y Abd ar-Rahmãn III (912-961), el primer califa cordobés, cuyo interés por los libros llegó a oídos del emperador de Bizancio Constantino Porfiroguénetos, que, para ganarse su amistad, le obsequió la "Materia médica" de Dioscórides, obra que sería traducida del griego al árabe con el concurso del monje Nicolás especialmente enviado para ese propósito por el emperador y Hasdai Ibn Shaprut (915-c-970-990), el canciller y médico judío del califa que era además políglota.

\footnotetext{
${ }^{34}$ Véase Usama b. Munqid (2000), Libro de las experiencias. Traducción y notas de Almudena García Algarra. Madrid: Editorial Gredos.

${ }^{35}$ M. El Abbadi: 1999, p. 193.
} 
El hijo y sucesor de Abd ar-Rahmãn, al-Hákam II (961-76), tuvo la suerte de llegar al trono cuando tenía cerca de 50 años, lo que le permitió dedicarse a la formación de su biblioteca y al estudio. Incluso prefería los libros a los asuntos de gobierno. Hombre de cultura enciclopédica, escribió una "Historia de al-Ándalus”, aunque su especialidad fue la genealogía en la que llegó a ser considerado una gran autoridad. Protector de hombres estudiosos, a los que acogía con generosidad, su fama se debe principalmente a su biblioteca que llegó a reunir cerca de 400 mil volúmenes. El eminente arabista e islamólogo holandés Reinhart Dozy (1820-1883) en su pormenorizado trabajo sobre la España islámica, nos ofrece estos datos ejemplares sobre el califa al-Hákam II: «Nunca habia reinado en España principe tan sabio, y aunque todos sus predecesores habian sido hombres cultos, aficionados a enriquecer sus bibliotecas, ninguno buscó con tal ansia libros preciosos y raros. En El Cairo, en Bagdad, en Damasco y en Alejandría, tenia agentes encargados de copiarle o de comprarle a cualquier precio libros antiguos y modernos. Su palacio estaba lleno, era un taller donde no se encontraban más que copistas, encuadernadores y miniaturistas. Sólo el catálogo de su biblioteca se componía de cuarenta y cuatro cuadernos, de veinte hojas, según unos, de cincuenta según otros, y no contenía más que el título de los libros, no su descripción. Cuentan algunos escritores que el número de volúmenes subia a cuatrocientos mil. Y Haquem los habia leido todos, y lo que es más, habia anotado la mayor parte [...] Libros compuestos en Persia y en Siria le eran conocidos, muchas veces antes que nadie los hubiera leido en Oriente» ${ }^{36}$.

Al frente de la biblioteca, instalada en el propio alcázar de Córdoba, estaba el ayudante de al-Hákam, llamado Talid, a cuyas órdenes trabajaban copistas, entre ellos dos mujeres, Lubna y Fátima, iluminadores, encuadernadores y una serie de eruditos encargados de la colación o corrección de las copias. Tenía el califa, además, un copista a sueldo en Bagdad para que copiara obras desconocidas en al-Ándalus. También tenía representantes en diversas capitales de Oriente para comprarle libros.

Según el historiador y sociólogo Ibn Jaldún (1332-1406), al-Hákam se hizo reservar la primera edición del libro de Abu al-Faraÿ al-Isfahani (ca. 897-967), Kitab al-Aghani al-kabir ('El mayor libro de canciones'), que tenía 24 tomos, y le envió la fuerte suma de mil dinares de oro. Cuando la obra, una de las máximas

\footnotetext{
${ }^{36}$ R. Dozy (1984), Historia de los Musulmanes de España. Madrid: Ediciones Turner, Tomo III, El Califato, V, pp. 97-98.
} 
y más preciosas de la literatura árabe, llegó a las manos del califa, éste quedó tan fascinado con ella que le giró otros mil dinares al autor, algo que difícilmente se haría en nuestros días.

No es ésta la única biblioteca que poseyeron los gobernantes hispanomusulmanes, que generalmente fueron alabados por su cultura. Tanto los emires previos al califato, como los posteriores reyes de taifas (Sevilla, Toledo, Almería, Valencia, Zaragoza, Badajoz, etc.), los califas almohades y los sultanes de Granada contaron con colecciones importantes.

También hubo numerosas bibliotecas privadas, algunas de modestos maestros de escuelas. Otras incluso de mujeres bibliófilas, como la rica Aisha, con grandes aficiones literarias y habilidad como copista, que vivió soltera y terminó formando una de las colecciones bibliográficas más importantes de Córdoba, ciudad en la que abundaron las colecciones de libros. Por ello la producción de libros en el mundo musulmán clásico, entre los siglos IX y XVI fue enorme. Según el arabista español con Julián Ribera y Tarragó (1858-1934), ésta llegó a ser de sesenta a ochenta mil ejemplares al año ${ }^{37}$. En el siglo X había centenares de copistas. Sólo en el arrabal oriental de Córdoba había 170 mujeres dedicadas exclusivamente a la copia de códices coránicos, que era una especialidad.

\section{ANEXO}

\section{Mitómanos y detractores en la Argentina}

Entre la avalancha de acusaciones que señalan a los árabo-musulmanes como los autores de la destrucción de la "Biblioteca-hija" de Alejandría, hemos seleccionado cuatro ejemplos publicados en Argentina.

\section{Ricardo Roa}

El primero es muy reciente y lo firma Ricardo Roa, editor general adjunto del diario Clarín, el principal matutino de Buenos Aires. Se trata de un artículo intitulado “¿Hacia una democracia sin Justicia?” (Clarín, sábado 13 de abril de 2013, p. 3). Allí Roa, no sabemos si por desinformado, asegura que «Hacia

${ }^{37}$ J. Ribera y Tarragó (1928): “Bibliófilos y bibliotecas en la España musulmana”, Disertaciones y opúsculos, I. Madrid: Imprenta de Estanislao Maestre. 
el siglo tercero, el Califa Omar quemó la biblioteca de Alejandrì. Luego agrega: "También, que justificó esa barbaridad asi: "Si los libros que están ahi dicen lo mismo que el Corán no sirven de nada y si lo contradicen son peligrosos y hay que destruirlos"». El califa Omar Bin Al-Jattab, segundo califa del Islam (634-644), vivió en el siglo séptimo de la era cristiana y no en el tercero. Luego Roa repite las mentiras propaladas a lo largo de ocho siglos, lo que evidencia que toca de oído y desconoce el pentagrama de la historia.

\section{Leonardo Moledo}

El segundo ejemplo fue publicado también por el matutino Clarín (martes 25 de septiembre de 1990), en su suplemento de Ciencia y Técnica (p. 3), con el título “AAlgo se quemó en Alejandría!” y la signatura del escritor, matemático y periodista Leonardo Moledo (1947) que dice cosas como éstas: "La calurosa costumbre de quemar libros dista de ser un invento moderno. La Biblioteca de Alejandría, que fue la más grande de la antigüedad, terminó su larga vida al ser incendiada por el Califa Omar en el año 644, que lo hizo basándose en un curioso argumento: 'Los libros de la biblioteca o bien contradicen al Corán, y entonces son peligrosos, o bien coinciden con el Corán, y entonces son redundantes. Este razonamiento notable, que fue objeto de un exquisito comentario del filósofo argentino Tomás Simpson, costó a la memoria humana una buena cantidad de obras irrecuperables».

\section{Belisario Segón}

El tercer se refiere a la nota titulada “¡Prendan fuego!”, firmada por Belisario Segón y aparecida en El Tribuno de Salta (domingo 23 de febrero de 1986, pp. 4 y 5). De la misma extractamos estos párrafos donde el autor se permite insultar gratuitamente a los musulmanes: "Ese ejercicio perverso de prender fuego al saber escrito -pretextando cualquier motivo de tipo religioso, racial, politico o ideológicopasó a la historia con el nombre de 'omarismo' [...] ¿Cuando nace el 'omarismo'? Probablemente con la quemazón de la Biblioteca de Alejandría. Se sabe que la incineración de sus libros respondió a un programa de gobierno cuyo jefe -en ese entonces dueño de un gran imperio- fue el califa Omar. Él, al mando de un ejército de 4.000 hombres en nombre de Mahoma, entró a conquistar Egipto en el año 640. [...] Cuando llegó a tomar Alejandría, el oficial que comandó la patrulla que allanó la célebre. El ignorante Amrú, se dirigió a Omar y le detalló la cantidad de libros existentes. Sin ninguna curiosidad por los legendarios y miles de papiros que habia en los cientos de estantes, Omar -semianalfabeto y rudo-le espetó la siguiente frase a su miliciano: 
'Si esos escritos están conformes con el Corán, son inútiles, y si ocurre lo contrario no deben tolerarse'. Entonces Amrú, dando voces de mando, salió a quemar la Biblioteca de Alejandría, como venganza de los árabes que veían en sus guerras santas el reinado de Dios. Los volumenes y papiros fueron extraidos del edificio y enviados a las calderas de los baños de la ciudad. Sirvieron de combustible durante seis meses, perdiéndose el tesoro de la humanidad más preciado: los manuscritos originales de los mejores pensadores griegos, judios y egipcios. El 'omarismo' habia logrado su objetivo gracias a un grupo de sarracenos fanatizados. [...] El fanatismo de Omar, ¿hasta cuándo seguirá acechando a las obras maestras escritas y a las bibliotecas de todos los tiempos?".

\section{Jorge Luis Borges}

El último ejemplo son los versos finales del poema de Jorge Luis Borges (1899-1986) que llevan por título "Alejandría, 641 A.D.”:

«En el siglo I de la Hégira,

Yo, aquel Omar que sojuzgó a los persas

Y que impone el Islam sobre la tierra,

Ordeno a mis soldados que destruyan

Por el fuego la larga Biblioteca,

Que no perecerái ${ }^{38}$.

El escritor que simpatizó con las dictaduras de Videla y Pinochet, nunca se preocupó mucho por el rigor histórico. Así, repite las acusaciones y falsedades de los mitómanos y acusa sin pruebas al califa Omar Bin Al-Jattab, al que califica por su cuenta de sojuzgador (en lugar de libertador, como realmente lo fue de los persas, oprimidos por los sasánidas durante cuatro siglos), y de haber sido el destructor de una biblioteca inexistente. Además se equivoca con el año de la conquista árabe de Alejandría. No sucedió en 641 A.D., sino un año después, en 642 A.D.

El historiador y sociólogo argentino Juan José Hernández Arregui (19121974) desentraña la tramoya borgiana con este comentario: «Borges, intelectual, será orientalista, no por la exploración del sentido que duerme en el extraño sopor de las culturas asiáticas, sino por la ornamentación exótica que las recubre como una enredadera. Como todo poeta carente de inspiración apela a la sorpresa, que es una celada, una greguería, un pistoletazo del intelecto» ${ }^{39}$.

${ }^{38}$ J. L. Borges (2005), Obra Poética. Buenos Aires: Emecé Editores, pp. 475-476.

${ }^{39}$ J. J. Hernández Arregui (2005), Imperialismo y cultura. Buenos Aires: Peña Lillo - Ediciones Continente, p. 150. 


\section{Referencias bibliográficas}

Casson, Lionel (2002). Libraries in the Ancient World. New Haven, CT: Yale University Press.

Empereur, Jean-Yves (2002). Alexandria: Jewel of Egypt. New York: Harry N. Abrams.

Jevenois, Pablo de (2009). Biblioteca de Alejandría: El enigma desvelado. Lisboa: Esquilo,

Lee Too, Yun (2010). The Idea of the Library in the Ancient World. Oxford and New York: Oxford University Press.

MacLeod, Roy (Editor) (2002). The Library of Alexandria: Centre of Learning in the Ancient World. London and New York: I. B. Tauris.

Murray, Stuart A. P. (2012). The Library: An Illustrated History. New York: Skyhorse Publishing.

Pollard, Justin and Reid, Howard (2007). The Rise and Fall of Alexandria: Birthplace of the Modern World. New York: Penguin Books.

Riaño Alonso, Juan José (2005). Poetas, filósofos, gramáticos y bibliotecarios: Origen y naturaleza de la Antigua Biblioteca de Alejandría. Gijón: Ediciones Trea. 